\title{
PERANCANGAN PEMODELAN SISTEM PENENTUAN KEPUTUSAN UNTUK PEMILIHAN JURUSAN MENGGUNAKAN METODE PERBANDINGAN EKSPONENSIAL (MPE) PERGURUAN TINGGI DI JAWA BARAT
}

\author{
Andri Sahata Sitanggang \\ Universitas Komputer Indonesia \\ sahataandris@gmail.com/andri.sahata@email.unikom.ac.id \\ Citra Noviyasari \\ Universitas Komputer Indonesia \\ cia nova@yahoo.com
}

\begin{abstract}
ABSTRAK
Teknologi Informasi sangat memberikan banyak sekali kemudahan yang dapat dirasakan oleh kehidupan manusia. Salah satu contoh era teknologi informasi adalah dengan lahirnya komputer didalam kehidupan masyarakat..Komputer kini dirasakan sangat memberikan banyak sekali mamfaat yang tidak bisa lepas dari kehidupan manusia. Disetiap perusahaan maupun instansi, didalam pengolahan data nya sudah diterapkan dengan mengunakan komputer. Maka dari itu komputer bisa dijadikan aspek-aspek pendukung keputusan yang baik dan tepat dalam mengambil sebuah keputusan. Khususnya instansi yang terkait yaitu perguruan tinggi adalah hal yang terpenting ketika mereka menerapkan kegiatan belajar mengajar antara dosen dan para mahasiswa. Ini sangat penting diperhatikan jika perguruan tinggi ingin menghasilkan suatu lulusan yang baik dan berprestasi, maka perguruan tinggi harus mengambil langkah terdepan jika ingin mencapai hal tersebut. Hal yang dapat dibenahi adalah sistem penerimaan calon mahasiswa baru kesetiap perguruan tinggi negeri dan swasta di Indonesia. Mengapa demikian, dengan adanya suatu sistem yang terkomputerisasi maka akan memberikan kemudahan didalam menentukan pilihan jurusan yang ingin dipilih, Karena salah satu faktor terpenting adalah bagaimana para calon mahasiswa dapat menentukan pilihannya sesuai dengan minat dan bakat mereka. Sehingga didalam kegiatan belajar mengajar mereka akan optimal, tidak ada akan keluhan-keluhan yang menyebabkan mahasiswa tersebut mempunyai pikiran untuk tidak melanjutkan studinya. Maka sebaiknya sudah saatnya pihak perguruan tinggi untuk merubah sistem yang ada dengan membuat suatu sistem informasi untuk pemilihan jurusan bagi para calon mahasiswa sesuai dengan jurusan yang diinginkan. Dari hal inilah maka sebagai seorang peneliti ingin memberikan masukan dengan menghadirkan sebuah inovasi baru yaitu dengan membangun sistem informasi pemilihan jurusan bagi perguruan tinggi negeri maupun swasta di Indonesia.
\end{abstract}

Keyword : Sistem, Informasi, Pemilihan, Jurusan, Ekponensial

\begin{abstract}
Information Technology is providing a lot of convenience that can be felt by human life. One example of the era of information technology is the birth of computers in the life of society .. Computers are now perceived to provide a lot of mamfaat that can not be separated from human life. In every company or institution, in its data processing has been applied by using computer. Therefore the computer can be made aspects of decision support is good and appropriate in taking a decision. Particularly related institutions ie colleges are the most important thing when they apply teaching and learning activities between lecturers and students. This is very important if the college wants to produce a good graduate and achievement, then the college should take the lead if you want to achieve it. Things that can be addressed is a new student admissions system kesetiap public and private universities in Indonesia. Why is that, with the existence of a computerized system it will provide convenience in determining the choice of majors to choose, because one of the most important factor is how the prospective students can determine the choice according to their interests and talents. So that in their teaching and learning activities will be optimal, there will be no complaints that cause the student has a mind to not continue his studies. Then it should be time the college to change the existing system by making an information system for the selection of majors for prospective students in accordance with the desired department. From this case then as a researcher wants to provide input by presenting a new innovation that is by building a system of election information majors for public and private universities in Indonesia.
\end{abstract}

Keyword: System, Information, Selection, Programs, exponential

1. PENDAHULUAN

Perkembangan ilmu pengetahuan pun semakin pesat, salah satunya dibidang pendidikan.
Maka dibutuhkan tindakan dalam meningkatkan mutu dan mekanisme pelayanan dibidang pendidikan agar lebih berfungsi dengan baik, 
sehingga pendidikan dapat berkembang terus menerus secara efektif dan efisien supaya memberikan sumber daya manusia berkualitas dan produktif. Untuk itu banyak pendidikan saat ini yang didalamnya ikut serta peran Teknologi Informasi atau Information Technology (IT). Ada begitu banyak manfaat teknologi saat ini untuk mendukung pendidikan, misalnya cara mengajar yang menggunakan audio visual yang membantu masyarakat belajar lebih variatif dan kreatif.

Semua perguruan tinggi umumnya menggunakan komputer untuk mendukung pembelajarannya. Dari setiap perguruan tinggi sudah dipastikan ada pemilihan jurusan yang ditawarkan kepada para calon mahasiswanya. Ada spesifikasi dimana mahasiswa harus lebih teliti lagi untuk pemilihan minat dan bakatnya dalam memilih jurusan. Hal ini sangat penting untuk mendukung perkuliahan kedepannya apakah mahasiswa tersebut dapat mengikuti perkuliahan dengan baik atau tidak.

Permasalahan yang sering timbul adalah kebanyakan mahasiswa banyak memilih untuk pindah program studi di pertengahan perkuliahan karena mahasiswa salah memilih program studi yang mereka dapatkan dari selembaran brosur. Padahal itu tidak cukup membantu mahasiswa dalam menentukan penjurusan dalam artian kemampuan dan keahlian yang sesuai dengan keinginan mereka. Untuk itu perlu adanya pengujian kepada mahasiswa baru yang akan kuliah di berbagai perguruan tinggi berbasis website yang harus diikuti semua mahasiswa baru. Hal ini diperlukan supaya mahasiswa tidak menyesal pada saat perkuliahan maupun akhir perkuliahan dan mengikuti perkuliahan dengan baik serta dengan prestasi yang baik juga.

Maka pihak perguruan tinggi harus mampu memberikan sebuah keputusan penting untuk setiap program studi yang ada, maka disinilah peran suatu teknologi informasi yaitu menggunakan komputer dapat berperan sebagai pengambilan keputusan.

\section{LANDASAN TEORI \\ Pengertian Sistem}

Sistem menurut menurut Abdul Kadir (2003 : $64)^{[1]}$ dalam buku yang berjudul Pengenalan Sistem Informasi, yang dimaksud dengan "sistem adalah sekelompok elemen/bagian-bagian berkaitan atau terpadu dengan maksud untuk mencapai suatu tujuan tertentu".

Menurut Bonnie Soeherman \& Marion Pinontoan (2008 : 3) ${ }^{[2]}$ dalam buku yang berjudul "Designing Information System, Concept \& Cases with Visio", "sistem dapat diartikan sebagai serangkaian atau sekelompok komponenkomponen yang saling mempunyai interaksi dan saling bekerja sama untuk menggapai tujuan tertentu."

Berdasarkan definisi di atas dapat disimpulkan bahwa sistem adalah suatu wadah atau media yang berisi sekumpulan elemen atau komponen yang saling mempunyai keterhubungan untuk mencapai suatu tujuan tertentu.

\section{Pengertian Informasi}

Menurut Bonnie Soeherman \& Marion Pinontoan (2008: 4) ${ }^{[2]}$ dalam buku yang berjudul Designing Information System, Concept \& Cases with Visio, "Informasi merupakan hasil pengolahan data (fakta/kejadian) menjadi sesuatu yang memiliki makna dan bernilai untuk pengambilan keputusan ".

Menurut Abdul Kadir (2003 : 32 $)^{[1]}$ dalam buku yang berjudul Pengenalan Sistem Informasi, "Informasi memiliki kandungan "makna/arti " adalah hal penting, karena berdasarkan pengertian itulah si penerima informasi dapat mengerti dan mendalami informasi tersebut dan secara lebih spesifik dapat menggunakannya untuk mengambil kesimpulan atau membuat keputusan."

Berdasarkan definisi di atas dapat disimpulkan bahwa informasi adalah suatu hasil pengolaha data oleh seseorang yang menggunakan yang bermamfaat dan dipakai untuk membuat keputusan.

\section{Pengertian Sistem Informasi}

Menurut Indrajani $(2011: 3)^{[3]}$ dalam buku yang berjudul Pengantar dan Sistem Basis Data, "Sistem informasi merupakan gabungan terpadu yang dari sekumpulan manusia, perangkat keras, perangkat lunka, jaringan komunikasi, dan sumber data, yang mempunyai fungsi sebagai penguumpulan, pengubah,dan penyebar informasi dalam sebuah organisasi/kumpulan".

Menurut Abdul Kadir (2003: 10) $)^{[1]}$ dalam buku yang berjudul Pengenalan Sistem Informasi, "Sistem informasi melingkupi komponen (kelompok manusia, kumpulan komputer, kumpulan teknologi informasi, dan prosedur kerja), memiliki bagian yang diproses (data menjadi informasi), dengan tujuan untuk mencapai suatu sasaran atau tujuan".

Menurut Bonnie Soeherman \& Marion Pinontoan (2008: 5) ${ }^{[2]}$ dalam buku yang berjudul Designing Information System, Concept \& Cases with Visio, "Sistem informasi merupakan serangkaian bagian yang memiliki komponen berupa manusia, prosedur, data, dan teknologi (misalkankomputer) untuk melakukan kegiatan berupa proses untuk menghasilkan atau memberikan informasi yang bernilai untuk orang yang akan membuat pengambilan keputusan".

Berdasarkan definisi di atas,"sistem informasi adalah kumpulan manusia-manusia yang teridiri dari manusia,teknologi dan prosedur untuk melakukan kegiatan proses dan menghasilkan.dan memberkan informasi untuk mencapai suatu tujuan atau sasaran dan mengambil suatu keputusan".

\section{Metode Perbandingan Eksponensial (MPE)}

Pengertian Menurut Marimin (2005: 21) ${ }^{[4]}$ dalam buku yang berjudul Teknik dan Aplikasi Pengambilan Keputusan dengan kriteria Majemuk, "Metode Perbandingan Eksponensial (MPE) merupakan metode untuk menentukan atau mendefinisikan rangkaian urutan prioritas alternatif/tambahan keputusan dengan kriteria tertentu".

Adapun Prosedur Metode Perbandingan Eksponensial mempunyai beberapa tahap, yaitu :

1. Menyusun alternatif

2. Menentukan kriteria atau perbandingan. 
3. Menentukan tingkat kepentingan/keperluan kriteria keputusan

4. Melakukan penilaian dan pengukuran kepada semua alternatif/tambahan

5. Menghitung keseluruhan nilai total setiap alternatif/tambahan yang memiliki kriteria

6. Menghasilkan dan menentukan rangkaian urutan prioritas keputusan didasarkan pada nilai total masing-masing alternatif yang memiliki kriteria

Formula perhitungan skor untuk setiap alternatif dalam metode perbandingan eksponensial adalah sebagai berikut :

Jumlah Nilai $J N x \sum_{y=1}^{a}(R K x y) B y$

Keterangan :

$\mathrm{JN} x=$ Total nilai alternatif ke- $\mathrm{x}$

$\mathrm{RK} x \mathrm{y}=$ Derajat kepentingan relatif kriteria ke-y pada pilihan keputusan $\mathrm{x}$

$\mathrm{TKKy}=$ Derajat kepentingan kriteria keputusan ke-y; TKKj > 0; bulat

$\mathrm{a} \quad=$ jumlah pilihan keputusan

$\mathrm{b}=$ jumlah kriteria keputusan

"Pemberian hasil Penentuan tingkat kepentingan bagian yang memiliki kriteria dapat dilakukan dengan cara memberikanwawancara kepada pakar atau melalui kesepakatan atau perundingan untuk berpendapat. Dan untuk penentuan skor alternatif pada kriteria tertentu dapat dilakukan dengan member nilai setiap alternatif berdasarkan nilai kriterianya. Semakin besar nilai alternatif semakin besar pula skor alternatif tersebut. Total skor masing-masing alternatif keputusan relatif berbeda".

\section{Perangkat Lunak Pendukung}

Dalam melakukan peneltian ini dibutuhkan alat Untuk membuat/mencapai sistem informasi yang terkomputerisasi yaitu membutuhkan perangkat lunak, yang berfungsi sebagai alternatif pendukung dalam membuat sistem informasi tersebut. Adapun perangkat lunak pendukung yang digunakan peneliti adalah "Hypertext Preprocessor (PHP)", "Apache", dan "MySQL"

\section{PHP Hypertext Preprocessor (PHP)}

Menurut M. Rudyanto Arief $(2011: 43)^{[5]}$ dalam buku yang berjudul Pemrograman Web Dinamis menggunakan PHP dan MySQL, "PHP (PHP Hypertext Preprocessor) adalah bahasa server-side scripting bersatu dengan pemrograman HTML dalam membentuk sebuah halaman website yang dinamis dan userfriendly". Karena PHP adalah server-side scripting sehingga kode-kode HTML dan perintah-perintah pemrograman PHP akan dijalankan pada server kemudian result akan dikirimkan ke client melalui browser dalam format HTML. Maka kode program yang dituangkan didalam PHP tidak akan terlihat dan ditampilkan kepada pengguna sehingga keamanan halaman web lebih terjamin. Pemrograman PHP inl dibentuk dengan tujuan untuk membuat sebuah halaman website yang dinamis.

\section{Apache}

Menurut M. Rudyanto Arief $(2011: 20)^{[5]}$ dalam buku yang berjudul Pemrograman Web Dinamis menggunakan PHP dan MySQL, "Apache adalah web server yang berfungsi untuk semua sistem operasi dalam menampilkan web".. Web server

Apache yang mendukung PHP. Port yang digunakan oleh web server di komputer default-nya adalah 80 . Kebanyakan web server yang berbasis open source seperti Apache mampu mendukung banyak sistem operasi. Web server Apache mampu berjalan di beberapa sistem operasi seperti Microsoft Windows, Linux, Solaris, Mac OS X.

\section{MySQL}

Menurut Betha Sidik $(2005: 1)^{[6]}$ dalam buku yang berjudul MySQL untuk pengguna, Administrator, dan Pengembang Aplikasi Web,

"Mysql adalah software untuk sistem manajemen data untuk digunakan dalam pemrograman web".

MySQL merupakan database yang paling populer digunakan untuk membangun aplikasi web yang menggunakan database sebagai sumber dan pengelola datanya.

\section{METODE PENELITIAN}

Adapun metode penelitian mencakup terdiri dari Metode pengembangan, objek penelitian,,desain penelitian, teknik pengumpulan data,.

\section{Tahapan Penelitian}

Adapun tahapan penelitian mengacu kepada metode pengembangan waterfall. Adapun tahapannya sebagai berikut

1. Analisa sistem adalah Tahapan analisis dalam mengembangan program. Tahap ini merupakan tahap awal dalam pengembangan sistem, adapun hal-hal yang dilakukan yaitu :

a) Merumuskan masalah.

b) Menyusun solusi dari masalah yang dihadapi.

c) Memilih kriteria atau perbandingan keputusan yang penting untuk dievakuasi.

d) Memilih tingkat kepentingan dari setiap kriteria keputusan.

2. Desain Sistem adalah tahapan dalam menerjemahkan sistem yang dibuat agar lebih di mengerti oleh pemakai. Yaitu dengan cara menampilkan ke dalam Diagram Konteks, Data Flow Diagram (Diagram Aliran Data), Entity Relationship Diagram, Struktur tabel, dan Struktur Menu.

3. Pembuatan sistem adalah tahapan pembuatan sistem yang menggunakan bahasa pemrograman yang sudah ditentukan.

4. Pengujian Program adalah tahapan untuk menguji sistem yang dibuat. Dalam tahapan ini peneliti menggunakan pengujian blackbox, dengan tujuan agar sistem dapat berfungsi sesuai kebutuhan user.

5. Implementasi dan Pemeliharaan adalah tahapan dimana program yang sudah dibuat dapat diperbaiki kembali sesuai kebutuhan user. Hal ini dapat dilakukan secara optiional. 


\section{Metode Pendekatan}

Metode pendekatan sistem yang digunakan pada penelitian ini menggunakan metode perancangan sistem terstruktur yaitu suatu pendekatan proses untuk mendefinisikan urutan urutan dalam membuat sebuah sistem. Adapun alat-alat (tools) yang membantu dalam perancangan terstruktur ini adalah Data Flow Diagram (DFD), Entity Relationship Diagram (ERD), dan lainnya.

\section{Desain Penelitian}

Adapun desain penelitian dpat dilihat pada gambar 4.1

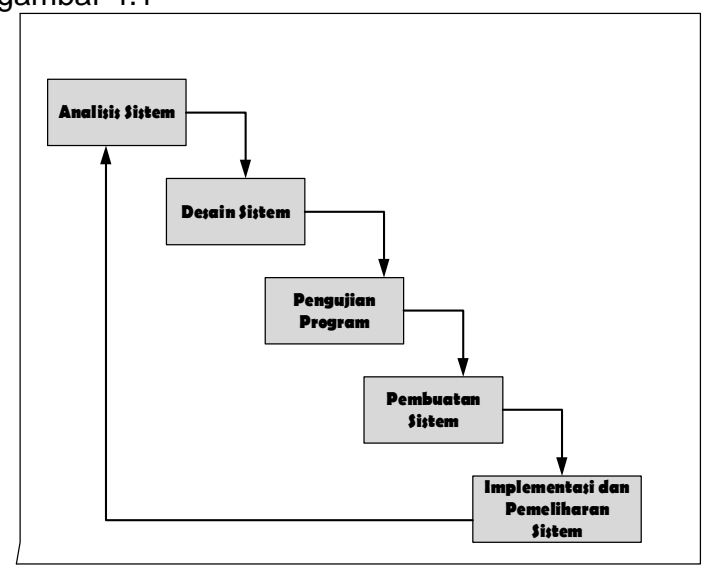

Gambar 3.1 Desain Penelitian

\section{HASIL DAN PENELITIAN}

\section{Diagram Konteks}

Dari flow map yang diusulkan diatas maka diagram konteks yang diusulkan dapat dilihat dibawah ini.

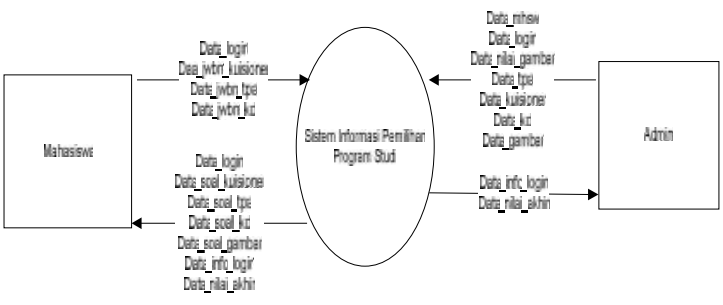

Gambar 4.1 Diagram Konteks Sistem Informasi Pemilihan Program Studi yang Diusulkan

\section{Data Flow Diagram}

Data flow diagram merupakan bagian dari analisis sistem berikut data flow diagram berdasarkan flow map dan diagram konteks yang diusulkan.

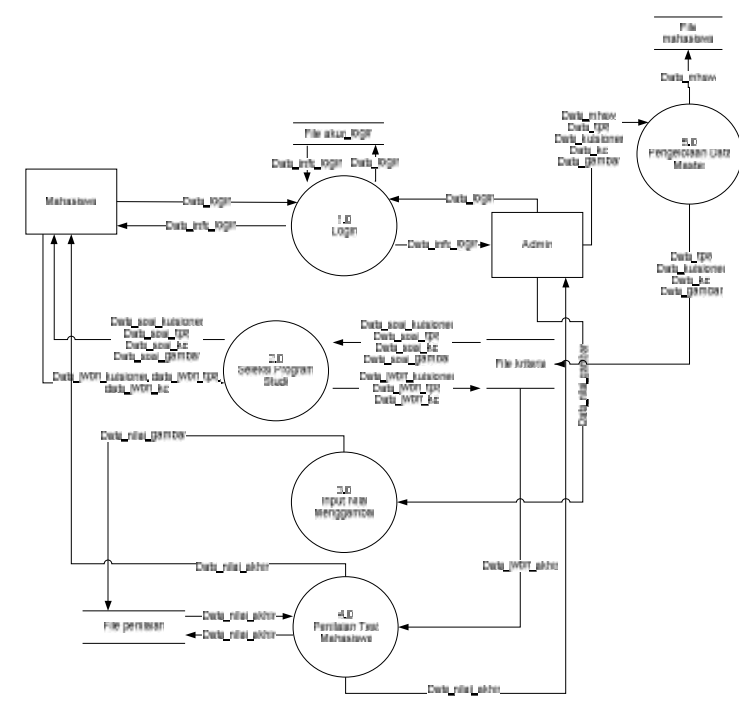

Gambar 4.2 DFD Level 1 yang diusulkan

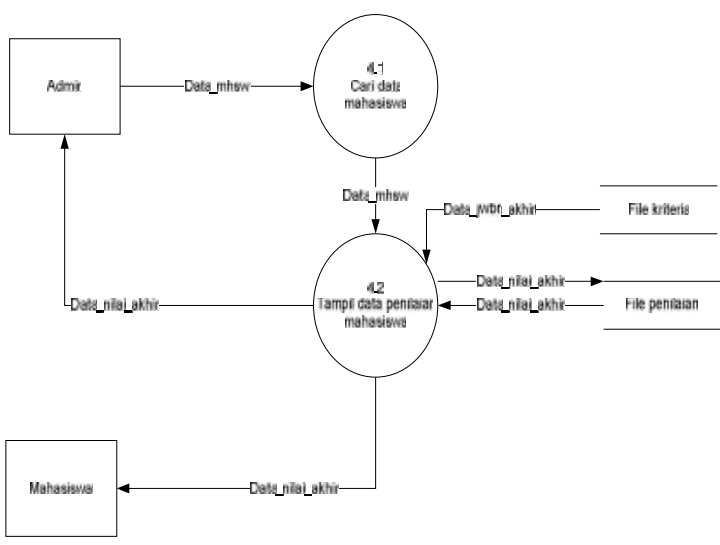

Gambar 4.3 DFD Level 2 Proses 4.0 Penilaian Test Mahasiswa

\section{Perancangan basis Data}

Normalisasi adalah proses yang menggambarkan atribut-atribut yang saling berelasi dan memiliki kunci utama atau primary key. Berikut bentuk-bentuk normalisasi.

\section{Bentuk tidak normal (Un-normal)}

Bentuk ini merupakan kumpulan data yang akan direkam, tidak ada keharusan mengikuti format tertentu, bisa tidak lengkap atau terduplikasi. Berikut ini merupakan bentuk tidak normal yaitu :

\{ username, password, status login, id pert, id_kriteria, kuisioner, tahun_soal, id_format, tampil, id_tpa, id_kriteria, jenis_tpa soal_tpa, jwbn_a, jwbn_b, jwbn_c, jwbn_d, jwbn_e, jawaban, tahun_soal, id_format, tampil, id_kd, id_kriteria, soal, jwbn_a, jwbn_b, jwbn_c, jwbn_d, jwbn_e, jawaban, tahun_soal, id_format, tampil, id_gbr, id_kriteria, soal_gambar, gambar, prodi, tahun_soal, id_format, Id_penilaian, nim, nilai_tahap1, nilai_tahap2, nilai_tahap2, nilai_tahap3, nilai_gambar, nilai_akhir, status_layak, keterangan, id_penilaian, nim, nilai_tahap1, nilai_tahap2, nilai tahap2, nilai_tahap3, nilai_gambar, nilai_akhir, status_layak, keterangan, id_jwbn, id_kriteria, jwbn, bobot \} 


\section{Bentuk Normal 1 (1-NF)}

Suatu relasi dikatakan memenuhi kaidah 1NF jika hanya jika dalam relasi tersebut tidak terjadi pengulangan kelompok atribut. Bentuk 1 dari sistem informasi pemilihan program studi adalah sebagai berikut :

\{ username, password, status_login, id_pert, id_kriteria, kuisioner, tahun_soal, id_format, tampil, id_tpa, jenis_tpa soal_tpa, jwbn_a, jwbn_b, jwbn_c, jwbn_d, jwbn_e, jawaban, id_kd, id_gbr, soal_gambar, gambar, prodi, id_penilaian, nim, nilai_tahap1, nilai_tahap2, nilai_tahap2, nilai_tahap3, nilai_gambar, nilai_akhir, status_layak, keterangan, id_jwbn, jwbn, bobot $\}$

\section{Bentuk Normal 2 (2-NF)}

Relasi dikatakan memenuhi kaidah normal tingkat kedua jika memenuhi kaidah $1 \mathrm{NF}$ dan atribut yang bukan kunci harus bergantung pada atribut kunci. Pada bentuk normal tingkat kedua, semua atribut bukan kunci harus bergantung total pada semua atribut kuncinya. Bentuk 2-NF sistem informasi pemilihan program studi adalah sebagai berikut :

Mahasiswa $=\{$ nim, nama_mhsw, tempat, tgl_lahir, j_kelamin, alamat, no_telp, email, prodi, foto, status_login\}

Akun Login $=\left\{\right.$ username ${ }^{\star}$, password $\}$

Kriteria $=\left\{\right.$ id_kriteria* ${ }^{*}$ nama_kriteria, keterangan, bobot\}

Pertanyaan_kuisioner $=\left\{\right.$ id_pert ${ }^{*}$, kuisioner, tahun soal, tampil\}

Jwbn_kuisioner $=\left\{\right.$ id_jwbn* ${ }^{*}$ jwbn, bobot $\}$

Komp_dasar $=\left\{i d \_k d^{*}\right.$, soal, jwbn_a, jwbn_b, jwbn_c,jwbn_d, jwb̄n_e, jawaban, tahun_soal, tampil $\}$

Tpa $=\left\{\right.$ id_tpa* ${ }^{*}$ soal_tpa, jwbn_a,jwbn_b, jwbn_c, jwbn_d, jwbn_e, jawaban, tahun_soal, tampil\} Menggambar $=\{$ id_gbr* , soal_gbr, gambar, prodi, tahun_soal\}

Penilaian $=\{$ id_penilaian*, nilai_tahap 1 ,

nilai_tahap2, nilai_tahap3, nilai_gambar, nilai_akhir, status_layak, keterangan\}

\section{Bentuk Normal 3 (3-NF)}

Bentuk normalisasi ketiga dapat terpenuhi apabila berada dalam bentuk normal kedua, dan setiap atribut bukan kunci bergantung penuh pada kunci primer. Adapun bentuk normal ketiga adalah sebagai berikut :

Mahasiswa $=\{$ nim, nama_mhsw, tempat, tgl_lahir, j_kelamin, alamat, no_telp, email, prodi, foto, status login\}

Akun_login $=\left\{\right.$ username ${ }^{*}$, password, status_login** $\}$

Kriteria $=\left\{\right.$ id_kriteria* ${ }^{*}$ nama_kriteria, keterangan, bobot\}

Pertanyaan_kuisioner $=\left\{\right.$ id_pert* ${ }^{*}$ id_kriteria** kuisioner, tahun_soal, tampil $\}$

Jwbn_kuisioner $=\left\{\right.$ id_jwbn*, id_kriteria** ${ }^{\star}$ jwbn, bobot\}

Komp_dasar $=\left\{\mathrm{id} \_\mathrm{kd}^{*}\right.$, id_kriteria ${ }^{* *}$, soal, jwbn_a, jwbn_b, jwbn_c, jwbn_d, jwbn_e, jawaban, tahun_soal, tampil $\}$

Tpa $=\left\{\right.$ id_tpa ${ }^{*}$, id_kriteria** ${ }^{*}$, soal_tpa, jwbn_a, jwbn_b, jwbn_c, jwbn_d, jwbn_e, jawaban, tahun_soal, tampil\}
Menggambar $=\left\{\right.$ id_gbr ${ }^{*}$, id_kriteria** ${ }^{*}$, soal_gbr, gambar, prodi, tahun_soal $\}$

Penilaian $=\left\{\right.$ id_penilaian ${ }^{*}$, nim $^{\star *}$, nilai_tahap1 nilai_tahap2, nilai_tahap3, nilai_gambar, nilai_akhir, status_layak, keterangan \}

\section{Relasi Tabel}

Relasi

tabel merupakan proses pengelompokkan data yang terdiri dari entitasentitas dimana entitas tersebut saling berelasi yang berfungsi mengakses data item kedalam database dan mudah untuk dimodifikasi atau diperbaiki. Berikut relasi tabel database yang diusulkan yang terdapat di perguruan tinggi negeri dan swasta.

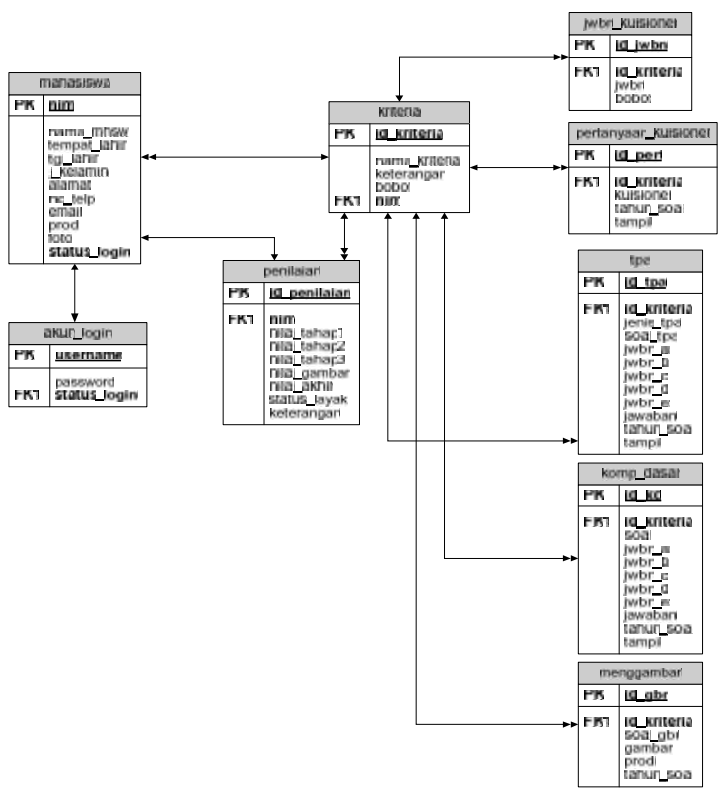

Gambar 4.4 Tabel Relasi Sistem Informasi Pemilihan Program Studi

\section{Entity Relationship Diagram}

Perancangan basis data yang digunakan adalah Entity Relationship Diagram (ERD). Entity Relationship Diagram adalah salah satu metode pemodelan basis data yang digunakan untuk menghasilkan skema konseptual untuk jenis/model data semantik sistem. Komponen utama ERD adalah entitas, atribut dan relasi. Entitas merupakan individu yang mewakili sesuatu yang nyata dapat dibedakan dari yang lain. Relasi merupakan hubungan diantara sejumlah entitas yang berasal dari entitas yang berbeda. Berikut Entity Relationship Diagram di perguruan tinggi.Negeri dan Swasta

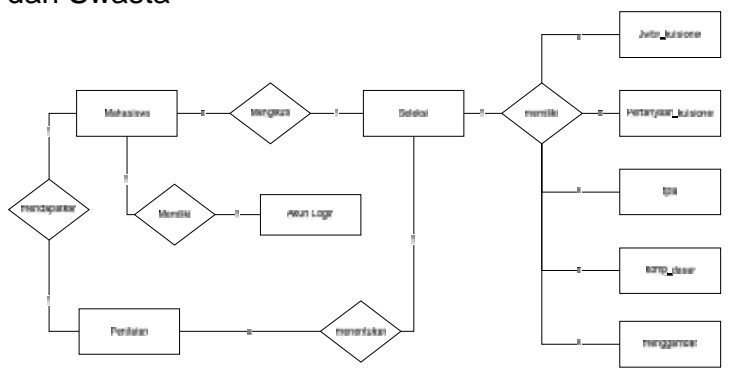

Gambar 4.5 ERD Sistem Pemilihan Program Studi 


\section{Penggunaan Program}

Sistem informasi pemilihan program studi berguna untuk menguji kembali setiap program studi yang sudah dipilih oleh mahasiswa. Mahasiswa harus mengikuti setiap seleksi kriteria yang sudah dibuat. Berikut tampilan sistem informasi pemilihan program studi.

1. Halaman Utama

Halaman ini adalah halaman dimana admin dan mahasiwa bisa login di halaman yang sama.

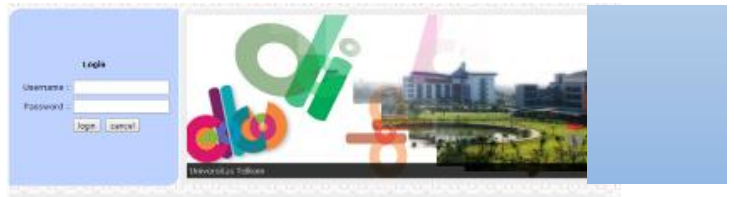

Gambar 5.1 Tampilan Halaman Utama

2. Halaman Mahasiswa

Halaman mahasiswa terdiri dari tampilantampilan berikut ini :

a. Tampilan Biodata Mahasiswa

Halaman ini untuk menampilkan biodata mahasiswa.

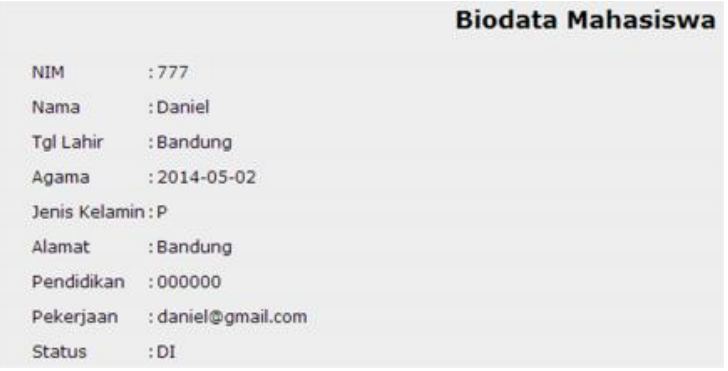

Gambar 5.2 Tampilan Biodata Mahasiswa

b. Tampilan Form Ubah Password

Mahasiswa dapat mengubah passwordnya dengan form ini.

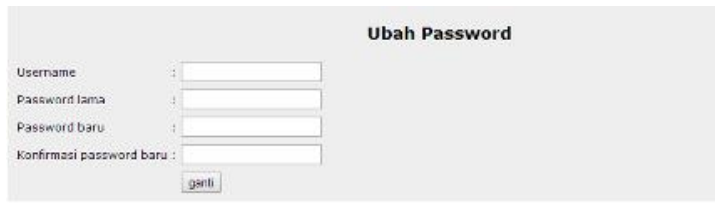

Gambar 5.3 Tampilan Form Ubah Password

c. Tampilan Seleksi Tahap I Kuisioner

Setelah login, mahasiswa dapat mengikuti seleksi tahap I yaitu kuisioner.

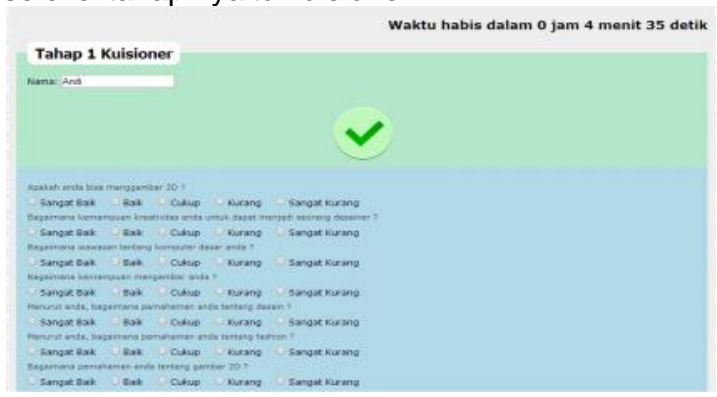

Gambar 5.4 Seleksi Tahap I Kuisioner d. Tampilan Seleksi Tahap II TPA

Setelah selesai seleksi tahap I, mahasiswa dapat mengikuti seleksi tahap II yaitu Test Potensi Akademik (TPA).

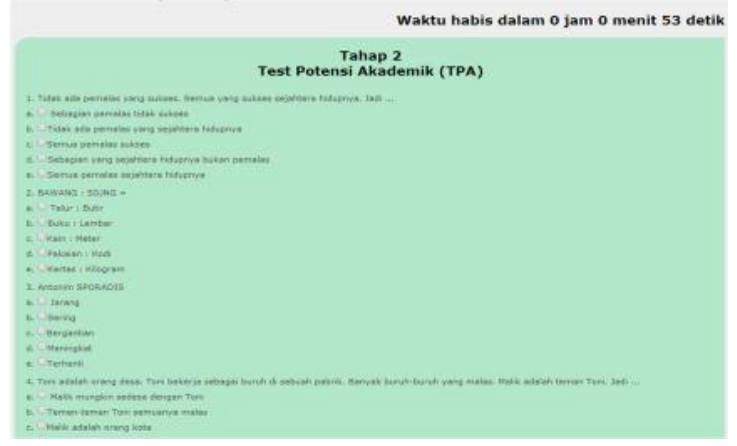

Gambar 5.5 Seleksi Tahap II TPA

e. Tampilan Seleksi Tahap III Komputer Dasar

Setelah selesai seleksi tahap II, mahasiswa dapat mengikuti seleksi tahap III yaitu Komputer Dasar.

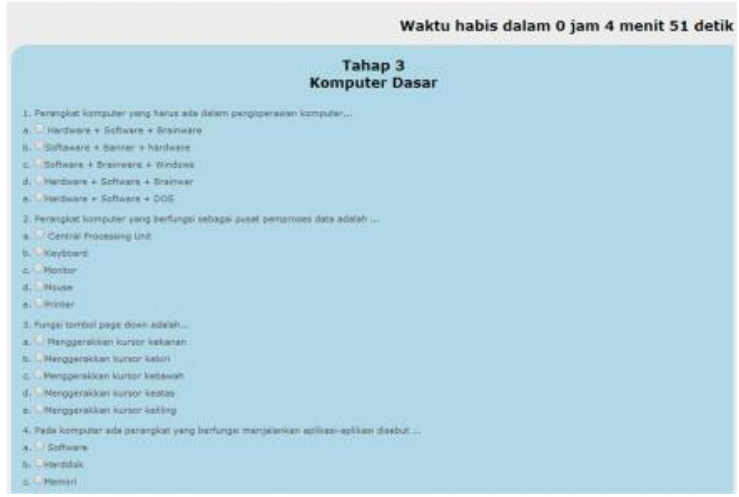

Gambar 5.6 Seleksi Tahap III Komputer Dasar

f. Tampilan Seleksi Tahap IV Menggambar

Setelah selesai seleksi tahap III, mahasiswa dapat mengikuti seleksi tahap IV yaitu Menggambar.

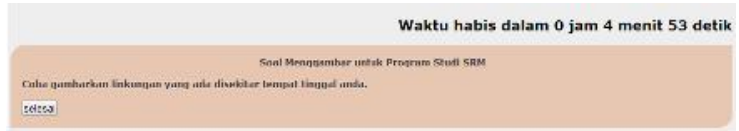

Gambar 5.7 Seleksi Tahap IV Menggambar

g. Tampilan Status Hasil Seleksi

Menu status menampilkan hasil seleksi apakah mahasiswa yang mengikuti seleksi lulus atau tidak.

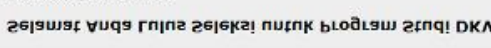

Gambar 5.8 Status Seleksi

3. Halaman Admin

Halaman admin terdiri dari tampilan-tampilan berikut ini :

a. Tampilan Data Master Mahasiswa 
Data master mahasiswa ini admin dapat mengelola data mahasiswa, seperti ubah dan hapus data sesuai dengan kebutuhan.

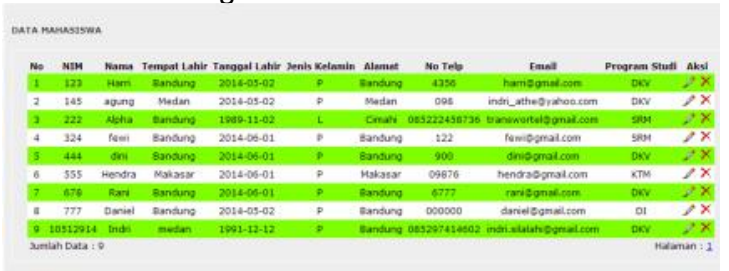

Gambar 5.9 Tampilan Data Master Mahasiswa

b. Tampilan Data Master Kriteria

Data master kriteria ini admin dapat mengelola data kriteria, seperti ubah dan hapus data sesuai dengan kebutuhan.

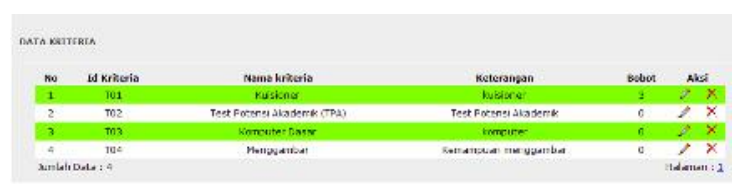

Gambar 5.10 Tampilan Data Master Kriteria

c. Tampilan Data Master Kuisioner

Data master kuisioner ini admin dapat mengelola data kuisioner, seperti tambah, ubah dan hapus data sesuai dengan kebutuhan.

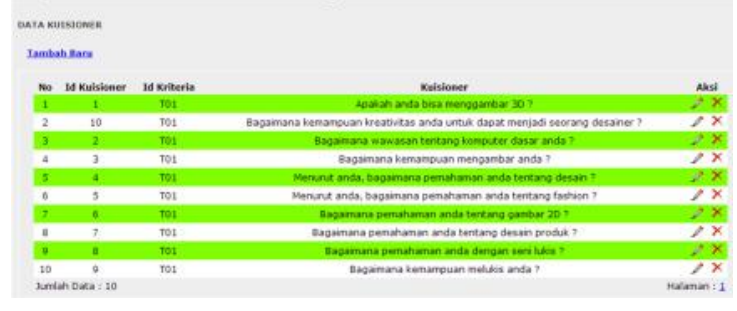

Gambar 5.11 Tampilan Data Master Kuisioner

\section{d. Tampilan Data Master TPA}

Data master TPA ini admin dapat mengelola data TPA, seperti tambah, ubah dan hapus data sesuai dengan kebutuhan.

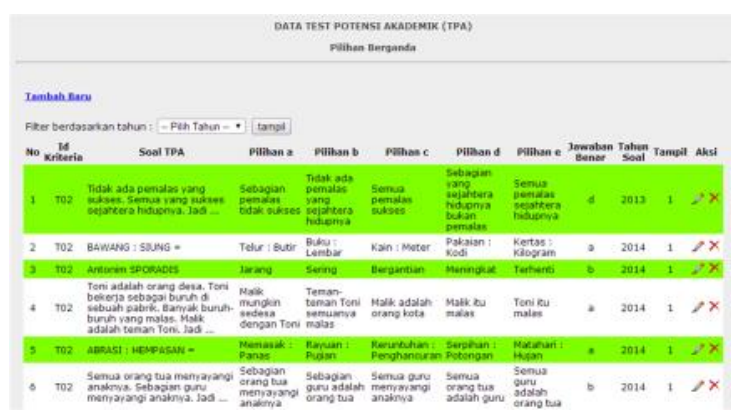

Gambar 5.12 Tampilan Data Master TPA

e. Tampilan Data Master Komputer Dasar

Data master komputer dasar ini admin dapat mengelola data komputer dasar, seperti tambah, ubah dan hapus data sesuai dengan kebutuhan.

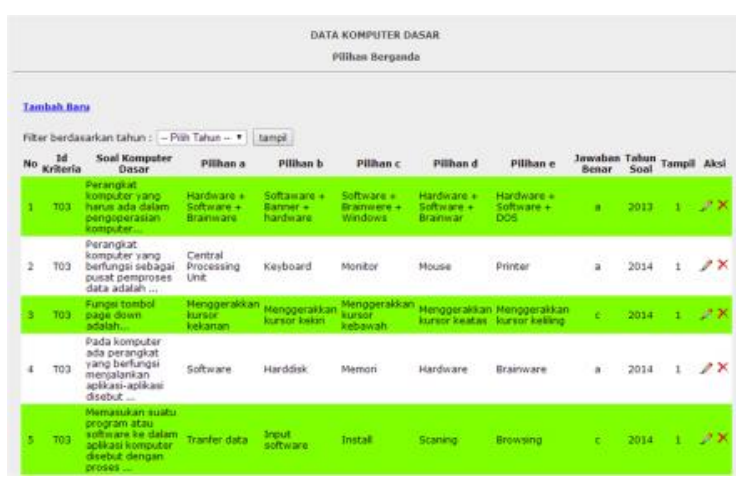

Gambar 5.13 Tampilan Data Master Komputer Dasar

f. Tampilan Data Master Menggambar

Data master menggambar ini admin dapat mengelola data menggambar, seperti ubah dan hapus data sesuai dengan kebutuhan.

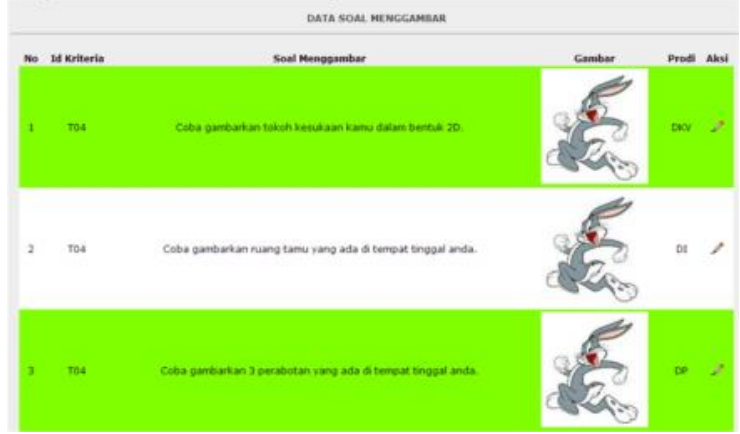

Gambar 5.14 Tampilan Data Master Menggambar

g. Tampilan Data Waktu Seleksi

Data master waktu seleksi ini admin dapat mengelola data waktu seleksi, seperti ubah dan hapus data sesuai dengan kebutuhan.

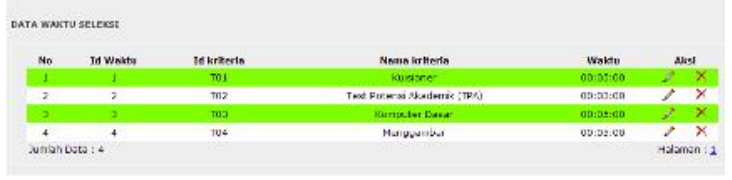

Gambar 5.15 Tampilan Data Master Waktu Seleksi

h. Tampilan Data Penilaian Mahasiswa

Admin dapat menginput nilai gambar setiap mahasiswa di menu ini. Secara otomatis maka akan keluar di text field nilai akhir mahasiswa. Ketika tidak lulus maka akan secara otomatis juga di tampilkan program studi alternatif yang sesuai dengan nilai setiap tahap mahasiswa.

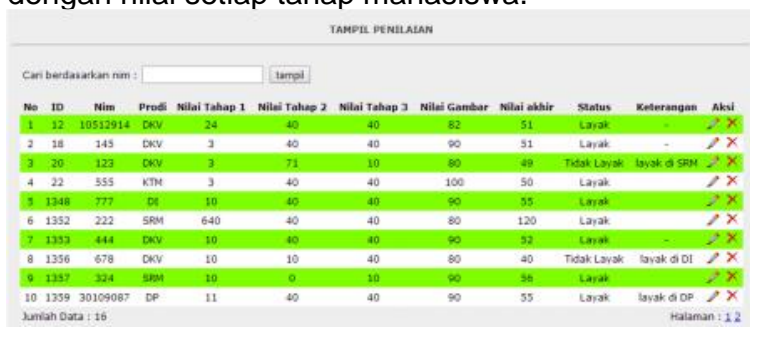

Gambar 5.16 Tampilan Data Penilaian Mahasiswa 
i. Tampilan Laporan Jumlah Kelulusan dari Setiap Program Studi

Di laporan ini akan ditampilkan jumlah mahasiswa yang lulus dan tidak lulus dari setiap program studi.

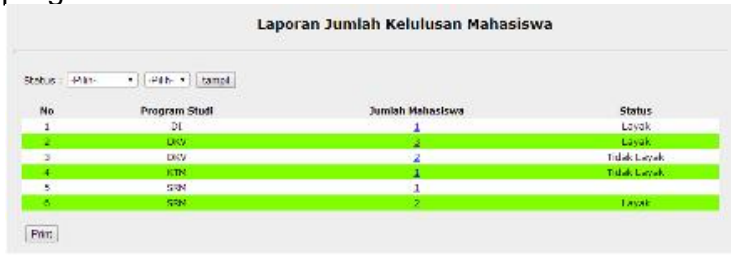

Gambar 5.17 Laporan Jumlah Kelulusan dari Setiap Program Studi

j. Tampilan Laporan Jumlah Mahasiswa yang Mengikuti Seleksi

Di laporan ini akan ditampilkan jumlah mahasiswa yang mengikuti seleksi dari setiap program studi.

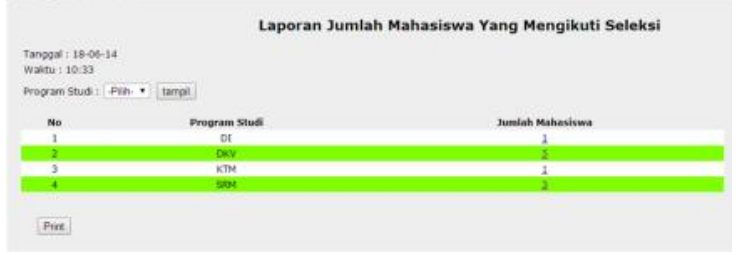

Gambar 5.18 Laporan Mahasiswa yang Mengikuti Seleksi

k. Tampilan Persentase Perhitungan

Admin dapat mengubah persentase penilaian seleksi dari setiap tahap sesuai dengan kebutuhan.

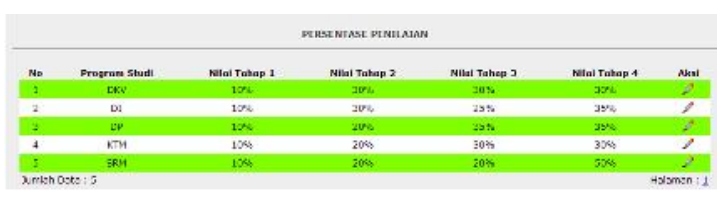

Gambar 5.19 Tampilan Persentase Perhitungan

I. Tampilan Pengaturan Menu Status Mahasiswa

Di menu ini admin dapat mengatur kapan menu status di halaman mahasiswa yang menampilkan hasil akhir seleksi ditampilkan.

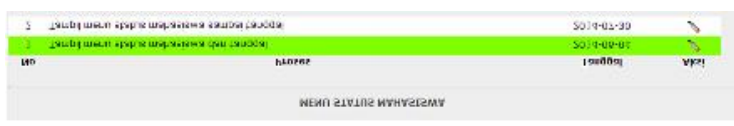

Gambar 5.20 Pengaturan Menu Status mahasiswa

m. Tampilan Setting Tahap Seleksi Program
Studi
Di menu ini. admin dapat mengatur dari setiap tahap format soal apa yang akan ditampilkan pada saat seleksi. Apakah format soal pilihan berganda atau benar salah.

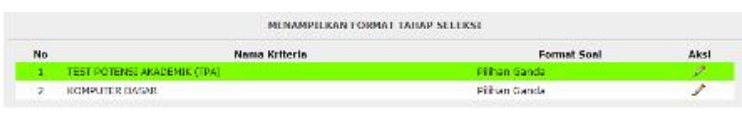

Gambar 5.21 Tampilan Setting Tahap Program Studi n. Tampilan Nilai Standar

$\mathrm{Di}$ menu ini mahasiswa yang tidak lulus seleksi akan di rekomendasikan ke program studi pilihan sesuai dengan nilai standar yang ada di menu ini.

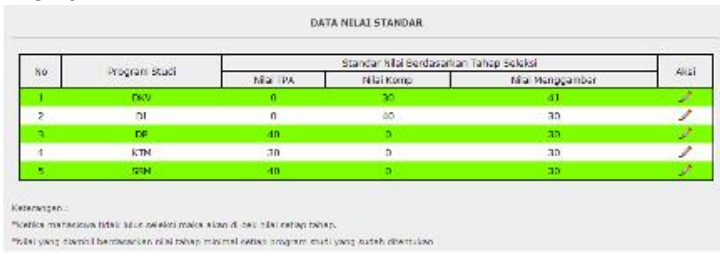

Gambar 5.22 Tampilan Nilai Standar

o. Tampilan Bank Soal

Di menu soal ini dapat ditampilkan bank soal dengan filter kriteria, format soal dan tahun soal.

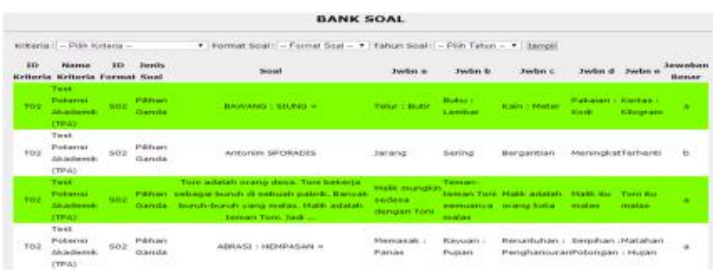

Gambar 5.23 Tampilan Bank Soal

\section{KESIMPULAN DAN SARAN}

\subsection{Kesimpulan}

Kesimpulan yang diambil dari sistem informasi pemilihan program studi yang telah dibangun adalah mahasiswa akan tahu dan mengerti program studi yang dipilih berdasarkan minat dan bakatnya. Maka dengan adanya sistem informasi ini akan mengurangi atau meminimalkan mahasiswa yang akan pindah ke program studi yang lain akibat tidak sesuai dengan minat bakatnya.

Selain itu juga informasi yang diberikan di brosur tentang program studi memiliki beberapa kekurangan yang mahasiswa tidak tahu, maka dengan sistem informasi ini juga pemilihan program studi dapat dilengkapi dengan seleksi dimana setiap mahasiswa akan diseleksi apakah program studi yang diambil sesuati dengan bakat setiap mahasiswa.

Serta bagian akademik dan bagian program studi dapat dipermudah dengan adanya sistem informasi ini untuk melakukan seleksi terhadap pemilihan program studi yang sudah dipilih oleh mahasiswa, dan pengelolaan data yang terkait.

\subsection{Saran}


1. Diharapkan Sistem informasi ini tidak hanya melakukan proses seleksi dengan empat tahap tetapi bisa juga ditambah sesuai dengan kebutuhan program studi masing-masing.

2. Adanya sistem pengambilan keputusan in juga berlaku untuk pemilihan program studi untuk semua jenis program studi perguruan tinggi dan negeri di Jawa Barat

\section{DAFTAR PUSTAKA}

[1] Kadir, Abdul. (2003). Pengenalan Sistem Informasi. Yogyakarta: Penerbit ANDI.

[2] Pinontoan, Marion. Soeheman. (2008). Designing Information System, Concept \& Cases with Visio. Jakarta: PT elex Media Komputindo.
[3] Indrajani, S. M. (2011). Pengantar dan Sistem Basis Data. Jakarta: PT Elex Media Komputindo.

[4] Marimin. (2005). Teknik dan Aplikasi Pengambilan Keputusan dengan kriteria Majemuk, cetakan kedua. Jakarta: Grasindo Jakarta.

[5] Arief, M. R. (2011). Pemrograman Web Dinamis menggunakan PHP dan MySQL. Yogyakarta: Penerbit ANDI.

[6] Sidik, B. (Bandung). MySQL untuk pengguna, Administrator, dan Pengembang Aplikasi Web. 2005: Penerbit INFORMATIKA 